\title{
Adverse effects of trichothiodystrophy DNA repair and transcription gene disorder on human fetal development
}

\author{
R Moslehi ${ }^{a, b}$, C Signore $^{c}$, D Tamura $^{d}$, JL Mills ${ }^{c}$, JJ DiGiovannad,e, MA Tucker ${ }^{f}$, J Troendleg, $^{\mathrm{d}}$, \\ T Ueda $^{d}$, J Boyle ${ }^{d}$, SG Khan ${ }^{d}$, K-S Oh ${ }^{d}$, AM Goldstein $^{\dagger}$, and KH Kraemer ${ }^{d}$ \\ aBiostatistics Branch, Division of Cancer Epidemiology and Genetics (DCEG), National Cancer \\ Institute (NCl), National Institutes of Health $(\mathrm{NIH})$, Department of Health and Human Services \\ (DHHS), Bethesda, MD, USA \\ ${ }^{b}$ Department of Epidemiology and Biostatistics, School of Public Health, and Cancer Research \\ Center, University at Albany, State University of New York (SUNY), NY, USA
}

'Epidemiology Branch, Division of Epidemiology, Statistics, and Prevention Research, Eunice Kennedy Shriver National Institute of Child Health and Human Development (NICHD), NIH, DHHS, Bethesda, MD, USA

dBasic Research Laboratory, Center for Cancer Research, NCI, NIH, DHHS, MD, USA

eDivision of Dermatopharmocology, The Warren Alpert Medical School of Brown University, Providence, RI, USA

fGenetic Epidemiology Branch, DCEG, NCI, NIH, DHHS, Bethesda, MD, USA

gBiostatistics and Bioinformatics Branch, Division of Epidemiology, Statistics, and Prevention Research, Eunice Kennedy Shriver NICHD, NIH, DHHS, Bethesda, MD, USA

\section{Abstract}

The effects of DNA repair and transcription gene abnormalities in human pre-natal life have never been studied. Trichothiodystrophy (TTD) is a rare (affected frequency of $10^{-6}$ ) recessive disorder caused by mutations in genes involved in nucleotide excision repair (NER) pathway and in transcription. Based on our novel clinical observations, we conducted a genetic epidemiologic study to investigate gestational outcomes associated with TTD. We compared pregnancies resulting in TTD-affected offspring $(n=24)$ with respect to abnormalities during their antenatal and neonatal periods to pregnancies resulting in their unaffected siblings $(n=18)$, accounting for correlation, and to population reference values. Significantly higher incidence of several severe gestational complications was noted in TTD-affected pregnancies. Small for gestational age (SGA) $<10$ th percentile [Relative risk $(\mathrm{RR})=9.3,95 \% \mathrm{CI}=1.4-60.5, \mathrm{p}=0.02]$, SGA $<3 \mathrm{rd}$ percentile $(\mathrm{RR}=7.2,95 \% \mathrm{CI}=1.1-48.1, \mathrm{p}=0.04)$, and neonatal intensive care unit (NICU)

(C) 2009 John Wiley \& Sons A/S

Corresponding author: Dr Roxana Moslehi, Cancer Research Center, SUNY at Albany, Room 310, 1 Discovery Drive, Rensselaer NY 12144, USA. Tel.: +1 518591 7225; fax: +1 518591 7201; rmoslehi@albany.edu.

Authors' Contributions

R. M. conceived this study in 2003 based on novel clinical observations (by R. M. and D. T.), conducted all interviews and medical record abstractions, helped with data analysis/interpretation and drafted the manuscript. C. S. helped with reviewing medical records, analyzing/interpreting data and drafting the manuscript. D. T. helped with clinical examination of families and obtaining and reviewing medical records. J. L. M. helped with data analysis/interpretation and drafting of the manuscript. J. J. D. and K. H. K. provided clinical examination of family members; K. H. K. supervised all laboratory analyses. M. A. T. and A. M. G. helped with study design development and implementation. J. T. conducted all statistical analyses for this project. T. U., J. B., S. K., and K.-S. O. provided the complementation group analysis. R. M. and C. S. proposed the hypothesis and mechanisms of the involvement of TTD genes in fetal and placental development. 
hospitalization $(\mathrm{RR}=6.4,95 \% \mathrm{CI}=1.4-29.5, \mathrm{p}=0.02)$ occurred more frequently among TTDaffected neonates compared with their unaffected siblings. Compared with reference values from general obstetrical population, pregnancies that resulted in TTD-affected infants were significantly more likely to be complicated by hemolysis, elevated liver enzymes and low platelets (HELLP) syndrome $(\mathrm{RR}=35.7,95 \% \mathrm{CI}=7.6-92.5, \mathrm{p}=0.0002)$, elevated mid-trimester maternal serum human chorionic gonadotropin $(\mathrm{hCG})$ levels $(\mathrm{RR}=14.3,95 \% \mathrm{CI}=7.0-16.6, \mathrm{p}<0.0001)$, SGA $<3$ rd percentile $(\mathrm{RR}=13.9,95 \% \mathrm{CI}=7.4-21.1, \mathrm{p}<0.0001)$, pre-term delivery $(<32$ weeks $)(\mathrm{RR}=$ $12.0,95 \% \mathrm{CI}=4.9-21.6, \mathrm{p}<0.0001)$, pre-eclampsia $(\mathrm{RR}=4.0,95 \% \mathrm{CI}=1.6-7.4, \mathrm{p}=0.006)$, and decreased fetal movement $(\mathrm{RR}=3.3,95 \% \mathrm{CI}=1.6-5.2, \mathrm{p}=0.0018)$. Abnormal placental development is an underlying mechanism that may explain the constellation of observed complications in our study. Thus, we hypothesize that TTD DNA repair and transcription genes play an important role in normal human placental development.

\section{Keywords}

development; DNA repair; human fetal; transcription; trichothiodystrophy genes

Trichothiodystrophy (TTD) is a rare (affected frequency of 1 in $10^{6}$ in Europe) (1) autosomal recessive disorder of DNA repair and transcription (2-4). TTD has a wide spectrum of clinical features that include sulfur-deficient brittle hair, small stature, mental retardation, ichthyotic skin, unusual facial features and in some cases photosensitivity $(5,6)$. Laboratory confirmation of the diagnosis of TTD is based on analysis of hair samples, which show alternating dark and light banding (tiger-tail) on polarizing microscopy $(7,8)$, reduced sulfur content of hair shafts $(7,8)$, and tests of DNA repair (4). TTD is caused by mutations in a number of genes, some with known functions involved in DNA repair pathways and in transcription. Photosensitive TTD can be caused by mutations in at least three genes: $X P D$ (ERCC2) and $X P B$ (ERCC3) which encode the two helicase subunits of transcription factor TFIIH (9-11) and TTD- $A$ (TFB5) which codes for the 10th subunit of TFIIH (12). TFIIH has various roles in several pathways including nucleotide excision repair (NER), basal transcription and activated transcription (13). Non-photosensitive TTD has been associated with mutations in TTDN1 (C7ORF11), a gene of unknown function on chromosome 7p14 $(14,15)$.

Patients with defects in NER genes may have several different phenotypes in addition to TTD including xeroderma pigmentosum (XP), Cockayne syndrome (CS), cerebro-ocularfacial syndrome (COFS) or combinations of XP/TTD, XP/CS and COFS/TTD $(3,4)$. Patients with XP have increased freckle-like pigmentation of their skin and a 1000-fold increase in risk for cancers of sun exposed tissues (skin and eyes) without hair abnormalities $(3,4)$. COFS has been considered as a severe form of CS and is a progressive brain and eye disorder with varying severity of several abnormalities including mental and physical retardation $(3,16)$. Individuals diagnosed with XP/TTD or COFS/TTD have phenotypic features of both disorders and mutations in the XPD gene; the exact risk of other abnormalities associated with these combined diagnoses is not known $(10,17)$.

Based on our novel clinical observations, we designed a genetic epidemiologic study in order to investigate pregnancy and human fetal developmental outcomes associated with defects in TTD genes. The specific objective of this study was to compare pregnancies resulting in TTD-affected individuals to pregnancies resulting in their unaffected siblings and to population reference values with respect to abnormalities noted during their antenatal and neonatal periods. For this purpose, obligate heterozygote (carrier) mothers of TTD patients referred to the National Institutes of Health $(\mathrm{NIH})$ were interviewed regarding the course of the pregnancies that produced the TTD-affected and unaffected children. 


\section{Materials and methods}

\section{Study population}

The mothers of all TTD patients followed at the NIH between 2001 and 2006 under a protocol to study the natural history of this disorder were approached for participation in this genetic epidemiologic study. The protocol was approved by the NCI institutional review board and appropriate written informed consent was obtained from all adult subjects and parents of minors. A total of 15 obligate heterozygote mothers had been recruited under the above protocol; all agreed to participate in the genetic epidemiologic study reported here.

\section{Data collection}

The mothers' reproductive, pregnancy, and delivery histories were collected using a detailed questionnaire. Quality assurance measures carried out prior to the initiation of the epidemiologic investigation included pre-testing of the questionnaire on volunteers as well as a pilot study of the questionnaire on mothers of patients with XP, which has genetic similarities with TTD. The questionnaire was then administered by telephone to the 15 obligate heterozygote mothers of the TTD patients. For quality control purposes, the epidemiologic questionnaire was re-administered to a subset of mothers during an in-person interview. All pertinent medical records were requested from hospitals, gynecologists, obstetricians, pediatricians and family doctors. We were able to obtain pertinent records on about two-thirds of the pregnancies of the mothers. An abstraction form was created to extract the necessary information from the records.

One member of the research group (R. M.) conducted the abstractions, pre- and pilot testing as well as all telephone and in-person interviews.

Data collected during the telephone interview and/or extracted from the medical records included pre-natal test results, mode of delivery, complications during pregnancy and/or delivery, gestational age at delivery, birth weight, head circumference, $1 \mathrm{~min}$ and $5 \mathrm{~min}$ APGAR scores, serial weight measurements in the nursery, neonatal infection, length of stay of the mother and the infant at the hospital after delivery, treatments received by mother or infant at the hospital prior to release, and birth defects or neurological symptoms present at birth or manifested within a few days after birth. A small for gestational age (SGA) infant was defined as an infant whose birth weight was below the 10th or 3rd percentile according to published standards accounting for infant sex (18).

\section{Statistical analysis}

TTD patients and their unaffected siblings were compared with respect to the complications noted during the course of the pregnancies that produced them and abnormalities noted during their neonatal periods. For each abnormality, the log-binomial model was assumed, allowing for an exchangeable correlation between siblings by using PROC GENMOD of Statistical Analysis System (SAS) Software (version 9.1, SAS Institute, Cary, NC). The logbinomial model gives estimated prevalence proportion ratios (PPR) for those with TTD compared with those without TTD. TTD patient characteristics were compared to reference values from vital statistics data for the 1996 US population (19) and from other sources of data on general obstetrical population (20-24) by Fisher's exact tests. All tests were twosided. Confidence intervals for relative risks (RRs) for comparisons against the US population were obtained from StatXact 4 for windows using the asymptotic method of Koopman (25). 


\section{DNA repair complementation group assignment}

Fibroblast cultures were established on TTD patients and assayed for DNA repair complementation groups by use of the plasmid host cell reactivation assay as previously described $(26,27)$.

\section{Results}

All eligible mothers contacted agreed to participate in the study. Table 1 summarizes the characteristics of the 15 obligate heterozygote mothers interviewed in this study. The majority of mothers were white, born in the United States, and had a college-level education. Sixty percent were $\$ 40$ years of age at the time of interview.

The pregnancy histories of the mothers are indicated in Table 2 . Forty percent of the mothers had two pregnancies, $47 \%$ had two live births and $67 \%$ had one affected child. The mother of family R12 had 12 pregnancies resulting in three miscarriages, one stillbirth, and eight live births; four of the live births of this subject were affected and diagnosed with XP/ TTD. There were 49 pregnancies among the 15 mothers, 47 singleton and 2 twin gestations. Among singletons, there were eight spontaneous abortions (fetal losses $<20$ weeks gestation) and one case of stillbirth (fetal loss at $\geq 20$ weeks gestation). TTD status for these pregnancy losses was not determined, and these pregnancies were excluded from comparative analyses. From the remaining 40 pregnancies, there were 24 live births with TTD (including four with XP/TTD and one with COFS/TTD) and 18 live births without TTD (Table 2). There was a ratio of three unaffected to four affected live births. The first affected live birth was the last pregnancy in 6 of the 15 families and the parents may have decided not to have additional children. This may explain the apparent deficiency of unaffected live births for this recessive disorder where a ratio of three unaffected to one affected would be expected by random mating.

In 12 of 15 families, the defective gene was determined through DNA repair complementation group assignment. Nine families were in complementation group XP-D; their offspring had the phenotype of TTD, COFS/TTD or XP/TTD. Two families were in complementation group TTD-A and another family had defects in TTDN1. The three families in whom the defective gene is unknown tested negative for complementation groups XP-D, XP-B, TTD-A, and TTDN1 (Table 2).

Table 3 describes pregnancy and neonatal outcomes among study participants. There were no significant differences in the proportion of males and females, as expected for a disorder with autosomal inheritance. Compared with pregnancies resulting in unaffected live births, low birth weight, SGA, and neonatal intensive care unit (NICU) admissions were significantly more common among TTD-affected pregnancies. Of note, 10 of the 13 (77\%) cases who were SGA were below the 3rd percentile for gestational age, suggesting that these were pathologically small and not merely constitutionally small infants.

Mothers also reported substantially decreased fetal movement for 13 (54.2\%) of their TTD pregnancies and for one unaffected pregnancy (data not shown). Concerns about decreased fetal movement were reported to the physicians for nine of the affected pregnancies (37.5\%) and the one unaffected pregnancy (5.6\%) (Table 3). Pre-eclampsia occurred more often in TTD-affected pregnancies (25.0\% vs 5.6\%). A particularly rare and severe form of preeclampsia, the hemolysis, elevated liver enzymes, and low platelets (HELLP) syndrome, was present in 3 of $24(12.5 \%)$ TTD-affected pregnancies, but in none of the unaffected pregnancies. Of the seven TTD-affected pregnancies, which had been offered mid-trimester maternal serum screening for neural tube defects (NTDs) and aneuploidy, six (85.7\%) had elevated levels of human chorionic gonadotropin (hCG) and four $(57.1 \%)$ had abnormal 
levels of alpha-fetoprotein (AFP) in addition to elevated hCG, although none had an NTD or aneuploidy. None of the four non-TTD pregnancies that were tested had abnormal levels of screening markers (Table 3). The comparisons noted above did not reach statistical significance.

To further examine the pregnancy problems in TTD cases, we compared rates of complications in TTD pregnancies to those in the general obstetrical population (20-24). As illustrated in Table 4 , there were highly statistically significant increased risks for elevated mid-trimester maternal serum hCG, low birth weight $(<2500$ and $<1500 \mathrm{~g})$, SGA infants $(<10$ th and $<3$ rd percentiles), preterm delivery ( $<37$ weeks and $<32$ weeks), pre-eclampsia and decreased fetal movement among TTD-affected pregnancies when compared with the general obstetrical population. The occurrence of HELLP syndrome among 12.5\% of TTDaffected pregnancies is particularly noteworthy, as this severe manifestation of preeclampsia has a baseline incidence of only 1-9 per 1000 live births (28).

Mothers were asked about any neonatal abnormalities or birth defects in their newborns. They reported skin abnormalities including congenital ichthyosis and collodion membrane in 12 affected babies, failure to thrive requiring tube feeding in eight affected newborns, hair abnormalities in seven affected newborns, nail abnormalities in four and poor sucking reflex in two affected babies. A severely affected pair of twins died shortly after birth. None of the unaffected individuals were reported to have any of the abnormalities noted above.

Laboratory confirmation of the diagnosis of TTD revealed characteristic tiger-tail banding of hair on polarized microscopy for all 22 living TTD patients in this study.

Placentas for 5 of 24 affected pregnancies were examined pathologically. Total or partial velamentous cord insertion was noted for four of five (80\%) placentas examined including both placentas of a set of affected twins. Placental infarction was also noted for four placentas, three of which were in one family and involved $>50 \%$ infarction of both placentas for a set of affected twins and infarction of one-third of the placenta for their affected sibling. Placenta of another affected pregnancy was noted as having several infarcts. Mass and/or cysts of unknown significance were reported for four placentas and one case of circumvallate placenta was also noted among this group.

Nearly all pregnancies resulting in offspring with TTD were associated with at least one gestational complication. The four pregnancies of family R12 in complementation group XP-D resulting in children with XP/TTD (Table 2) did not have a complication noted (Tables 3 and 4 ). Of the 18 pregnancies of the same mothers which resulted in unaffected offspring, $2(11 \%)$ were associated with a complication; one was the twin pregnancy of family R8 resulting in an affected and an unaffected neonate. Therefore, there was a strong association between TTD phenotype in the fetus and adverse pregnancy outcomes and gestational complications.

\section{Discussion}

We conducted a genetic epidemiologic investigation of the effects of TTD gene defects in prenatal life. We found highly significant increased risks of a number of pregnancy and gestational complications associated with TTD-affected pregnancies when compared with the unaffected pregnancies of the same mothers and with the rates in the general obstetrical population. As TTD is a rare disease, only small numbers of subjects and their pregnancies were available for study. Yet, even when comparing the small sample of TTD pregnancies to their unaffected siblings and adjusting for non-independence, we found a statistically significant, more than three-fold, increased risk of low birth weight, and a more than sevenfold increased risk of severe SGA $(<3$ rd percentile) in pregnancies where the infant was 
affected with TTD. Compared with population reference values, a greater than 35 -fold increased risk of HELLP syndrome and a more than 13-fold increased risk of severe SGA were observed. Elevated mid-trimester maternal serum hCG levels, pre-term delivery, and decreased fetal movement were also significantly more common among TTD-affected pregnancies.

The finding that nearly all offsprings with TTD or COFS/TTD, regardless of the defective gene involved, had at least one pre-natal complication suggests that TTD genes are important in normal human fetal development. Different mutations in XPD can cause different disorders including TTD, COFS/TTD and XP/TTD. In our study, gestational complications were noted in the TTD- and COFS/TTD-affected pregnancies with abnormalities in $X P D$ but not in the four XP/TTD-affected pregnancies with defects in $X P D$, therefore, the exact nature of the gene abnormalities may be of relevance with respect to prenatal complications. To our knowledge, this is the first report of adverse effects of DNA repair and transcription gene abnormalities on gestational outcomes in a systematic study.

Although each pregnancy complication noted in our study, if considered individually, could arise through more than one mechanism, impairment of placental development is a plausible mechanism that could explain the constellation of abnormalities observed in TTD-affected pregnancies. Pre-eclampsia, pre-term birth, and fetal growth restriction have been associated with impaired placental development and placental hypoxia (18, 29, 30). Emerging evidence indicates that in the absence of fetal conditions such as NTDs and aneuploidies, elevated mid-trimester maternal serum AFP levels and/or elevated levels of hCG, as observed in TTD-affected pregnancies in our study, are indicators of poor placentation and adverse pregnancy outcomes $(20,31)$. Decreased fetal movement, as was reported for the affected pregnancies in our study, is a well-recognized fetal response to a hypoxic intrauterine environment (32). Six of the affected pregnancies in our study were evaluated by a nonstress test (NST) due to concerns about baby's movement; NST yielded abnormal results in each of these cases.

Thus, the striking excess of presumed placentovascular complications in TTD-affected pregnancies compared with unaffected pregnancies in the same mother leads us to hypothesize that mutations in TTD genes may disrupt normal placental development, which may lead to the pregnancy and fetal developmental abnormalities noted in our study. As placental hypoxia can be caused by abnormalities in trophoblast invasion, it is possible that TTD gene mutations exert their effects on abnormal placental development through impairment of trophoblast invasion.

A number of TTD gene products, including XPD and TTD-A, are involved in both NER and transcription as subunits of TFIIH $(9,12)$. Although the role of TFIIH in transcription may be the relevant mechanism with respect to fetal development, the function of TFIIH in repair of oxidative damage may also be important in prenatal life. Studies in rodents have highlighted the importance of DNA repair pathways during mammalian organogenesis (33); it has been postulated that repair pathways play a role in the response of the conceptus to genotoxic agents, which may induce malformations $(34,35)$.

Previous human data on TTD genes and adverse pregnancy outcomes came from case reports that included perinatal problems in TTD patients as incidental findings. These have been summarized in two reviews $(5,6)$. Our findings with respect to the neonatal abnormalities of skin, hair and nail are in keeping with the previous reports. Other neonatal abnormalities observed at birth or in the nursery in our study such as poor sucking reflexes and failure to thrive are most likely related to the underlying conditions of pre-term birth and SGA. 
Although the placentas of the mothers in our study were not systematically evaluated, gross structural abnormalities of the placenta were noted in several TTD-affected pregnancies. Placental infarcts noted in our study are consistent with other findings of uteroplacental insufficiency. An intriguing finding of structural abnormalities of the placenta and cord such as velamentous cord insertion, normally seen in $1 \%$ of pregnancies in the general US population (19), was observed in at least 4 of $24(16.7 \%)$ TTD-affected pregnancies. The relevance of these structural abnormalities to the mechanisms leading to abnormal placentation needs further exploration. The observation that these severe pregnancy abnormalities recurred in subsequent affected pregnancies of the mothers in our study indicates that mothers of TTD patients should have their subsequent pregnancies monitored closely.

The strength of our study was the systematic epidemiologic approach and the study design employed for gathering data for which up to now the only data available were from incidental observations reported in case studies. One limitation of our study was the small number of TTD patients and unaffected siblings for comparison purposes; this limitation was unavoidable due to rarity of the TTD-affected individuals ( 1 in $10^{6}$ births) (1). Another limitation was the self-report of pregnancy complications by the mothers. We were, however, able to confirm the abnormalities reported for more than two-thirds of the pregnancies of the mothers in our study by reviewing birth and pregnancy records obtained from hospitals and obstetricians.

In conclusion, our systematic genetic epidemiologic investigation indicated a greatly increased risk of many adverse pregnancy outcomes such as SGA, HELLP syndrome, preeclampsia, pre-term delivery, and decreased fetal movement associated with abnormalities in TTD genes. Because abnormal placental development could explain the constellation of complications noted in our study; we hypothesize that TTD genes are important for normal placental development. The majority of TTD genes identified to date are involved in DNA repair and transcription; it is possible that mutations and polymorphisms in DNA repair or transcription genes contribute to adverse pregnancy outcomes associated with impaired placental development in the general population.

\section{Acknowledgments}

This study was supported by the Intramural Research Program of the DCEG and CCR, NCI, NIH and DHHS.

\section{References}

1. Kleijer WJ, Laugel V, Berneburg M, et al. Incidence of DNA repair deficiency disorders in western Europe: Xeroderma pigmentosum, Cockayne syndrome and trichothiodystrophy. DNA Repair (Amst). 2008; 7:744-750. [PubMed: 18329345]

2. Bootsma, D.; Kraemer, KH.; Cleaver, J.; Hoeijimakers, J. Nucleotide excision repair syndromes: xeroderma pigmentosum, Cockayne syndrome, and Trichothiodystrophy. New York: McGraw-Hill; 2002.

3. Kraemer KH, Patronas NJ, Schiffmann R, et al. Xeroderma pigmentosum, trichothiodystrophy and Cockayne syndrome: a complex genotype-phenotype relationship. Neuroscience. 2007; 145:13881396. [PubMed: 17276014]

4. Ruenger TM, DiGiovanna JJ, Kraemer KH. Hereditary diseases of genome instability and DNA repair. 2008

5. Itin PH, Sarasin A, Pittelkow MR. Trichothiodystrophy: update on the sulfur-deficient brittle hair syndromes. J Am Acad Dermatol. 2001; 44:891-920. quiz 921-894. [PubMed: 11369901]

6. Faghri S, Tamura D, Kraemer KH, et al. Trichothiodystrophy: a systematic review of 112 published cases characterises a wide spectrum of clinical manifestations. J Med Genet. 2008; 45:609-621. [PubMed: 18603627] 
7. Liang C, Morris A, Schlucker S, et al. Structural and molecular hair abnormalities in trichothiodystrophy. J Invest Dermatol. 2006; 126:2210-2216. [PubMed: 16728971]

8. Liang C, Kraemer KH, Morris A, et al. Characterization of tiger-tail banding and hair shaft abnormalities in trichothiodystrophy. J Am Acad Dermatol. 2005; 52:224-232. [PubMed: 15692466]

9. Broughton BC, Steingrimsdottir H, Weber CA, et al. Mutations in the xeroderma pigmentosum group D DNA repair/transcription gene in patients with trichothiodystrophy. Nat Genet. 1994; 7:189-194. [PubMed: 7920640]

10. Lehmann AR. DNA repair-deficient diseases, xeroderma pigmentosum, Cockayne syndrome and trichothiodystrophy. Biochimie. 2003; 85:1101-1111. [PubMed: 14726016]

11. Taylor EM, Broughton BC, Botta E, et al. Xeroderma pigmentosum and trichothiodystrophy are associated with different mutations in the XPD (ERCC2) repair/transcription gene. Proc Natl Acad Sci U S A. 1997; 94:8658-8663. [PubMed: 9238033]

12. Giglia-Mari G, Coin F, Ranish JA, et al. A new, tenth subunit of TFIIH is responsible for the DNA repair syndrome trichothiodystrophy group A. Nat Genet. 2004; 36:714-719. [PubMed: 15220921]

13. Bergmann E, Egly JM. Trichothiodystrophy, a transcription syndrome. Trends Genet. 2001; 17:279-286. [PubMed: 11335038]

14. Nakabayashi K, Amann D, Ren Y, et al. Identification of C7orf11 (TTDN1) gene mutations and genetic heterogeneity in nonphotosensitive trichothiodystrophy. Am J Hum Genet. 2005; 76:510516. [PubMed: 15645389]

15. Botta E, Offman J, Nardo T, et al. Mutations in the C7orf11 (TTDN1) gene in six nonphotosensitive trichothiodystrophy patients: no obvious genotype-phenotype relationships. Hum Mutat. 2007; 28:92-96. [PubMed: 16977596]

16. Graham JM Jr, Anyane-Yeboa K, Raams A, et al. Cerebrooculo-facio-skeletal syndrome with a nucleotide excision-repair defect and a mutated XPD gene, with prenatal diagnosis in a triplet pregnancy. Am J Hum Genet. 2001; 69:291-300. [PubMed: 11443545]

17. Broughton BC, Berneburg M, Fawcett H, et al. Two individuals with features of both xeroderma pigmentosum and trichothiodystrophy highlight the complexity of the clinical outcomes of mutations in the XPD gene. Hum Mol Genet. 2001; 10:2539-2547. [PubMed: 11709541]

18. Khong TY. Placental vascular development and neonatal outcome. Semin Neonatol. 2004; 9:255263. [PubMed: 15251142]

19. Ventura SJ, Martin JA, Curtin SC, et al. Report of final natality statistics, 1996. Mon Vital Stat Rep. 1998; 46:1-99.

20. Dugoff L, Hobbins JC, Malone FD, et al. Quad screen as a predictor of adverse pregnancy outcome. Obstet Gynecol. 2005; 106:260-267. [PubMed: 16055573]

21. Milunsky A, Jick SS, Bruell CL, et al. Predictive values, relative risks, and overall benefits of high and low maternal serum alpha-fetoprotein screening in singleton pregnancies: new epidemiologic data. Am J Obstet Gynecol. 1989; 161:291-297. [PubMed: 2475017]

22. Henry CS, Biedermann SA, Campbell MF, et al. Spectrum of hypertensive emergencies in pregnancy. Crit Care Clin. 2004; 20:697-712. ix. [PubMed: 15388197]

23. Sibai BM, Taslimi MM, el-Nazer A, et al. Maternal-perinatal outcome associated with the syndrome of hemolysis, elevated liver enzymes, and low platelets in severe preeclampsiaeclampsia. Am J Obstet Gynecol. 1986; 155:501-509. [PubMed: 3529964]

24. Froen JF. A kick from within-fetal movement counting and the cancelled progress in antenatal care. J Perinat Med. 2004; 32:13-24. [PubMed: 15008381]

25. Koopman BJ, van der Molen JC, Wolthers BG, et al. Capillary gas chromatographic determination of cholestanol/cholesterol ratio in biological fluids. Its potential usefulness for the follow-up of some liver diseases and its lack of specificity in diagnosing CTX (cerebrotendinous xanthomatosis). Clin Chim Acta. 1984; 137:305-315. [PubMed: 6421514]

26. Boyle J, Ueda T, Oh KS, et al. Persistence of repair proteins at unrepaired DNA damage distinguishes diseases with ERCC2 (XPD) mutations: cancer-prone xeroderma pigmentosum vs. non-cancer-prone trichothiodystrophy. Hum Mutat. 2008; 29:1194-1208. [PubMed: 18470933] 
27. Emmert S, Ueda T, Zumsteg U, et al. Strict sun protection results in minimal skin changes in a patient with xeroderma pigmentosum and a novel c.2009delG mutation in XPD (ERCC2). Exp Dermatol. 2009; 18:64-68. [PubMed: 18637129]

28. Bertakis KD, Hufford DB. Hemolysis, elevated liver enzymes and low platelet count. The HELLP syndrome. West J Med. 1986; 144:81-83. [PubMed: 3953075]

29. Kaufmann P, Black S, Huppertz B. Endovascular trophoblast invasion: implications for the pathogenesis of intrauterine growth retardation and preeclampsia. Biol Reprod. 2003; 69:1-7. [PubMed: 12620937]

30. Norwitz ER. Defective implantation and placentation: laying the blueprint for pregnancy complications. Reprod Biomed. 2006; 13:591-599. [Online].

31. Toal M, Chaddha V, Windrim R, et al. Ultrasound detection of placental insufficiency in women with elevated second trimester serum alpha-fetoprotein or human chorionic gonadotropin. J Obstet Gynaecol Can. 2008; 30:198-206. [PubMed: 18364097]

32. Olesen AG, Svare JA. Decreased fetal movements: background, assessment, and clinical management. Acta Obstet Gynecol Scand. 2004; 83:818-826. [PubMed: 15315592]

33. Vinson RK, Hales BF. DNA repair during organogenesis. Mutat Res. 2002; 509:79-91. [PubMed: 12427532]

34. McWhir J, Selfridge J, Harrison DJ, et al. Mice with DNA repair gene (ERCC-1) deficiency have elevated levels of p53, liver nuclear abnormalities and die before weaning. Nat Genet. 1993; 5:217-224. [PubMed: 8275084]

35. Niedernhofer LJ, Garinis GA, Raams A, et al. A new progeroid syndrome reveals that genotoxic stress suppresses the somatotroph axis. Nature. 2006; 444:1038-1043. [PubMed: 17183314] 


\section{Table 1}

Characteristics of Mothers of TTD Patients $(n=15)$

\begin{tabular}{lrr}
\hline Demographics & No. & $\%$ \\
\hline Race & 12 & 80.0 \\
White & 2 & 13.3 \\
Hispanic & 1 & 6.7 \\
Other & & \\
Country of birth & 11 & 73.3 \\
USA & 4 & 26.7 \\
Other & & \\
Highest level of education & & 6.7 \\
Less than high school & 1 & 26.7 \\
High school & 4 & 53.3 \\
College & 8 & 13.3 \\
Advanced degree & 2 & \\
Age at interview (Year) & & 26.0 \\
20-30 & 4 & 26.7 \\
31-40 & 5 & 33.3 \\
$41-50$ & 3 & 20.0 \\
$51-60$ & 3 & 20.0 \\
\hline & & \\
\hline
\end{tabular}




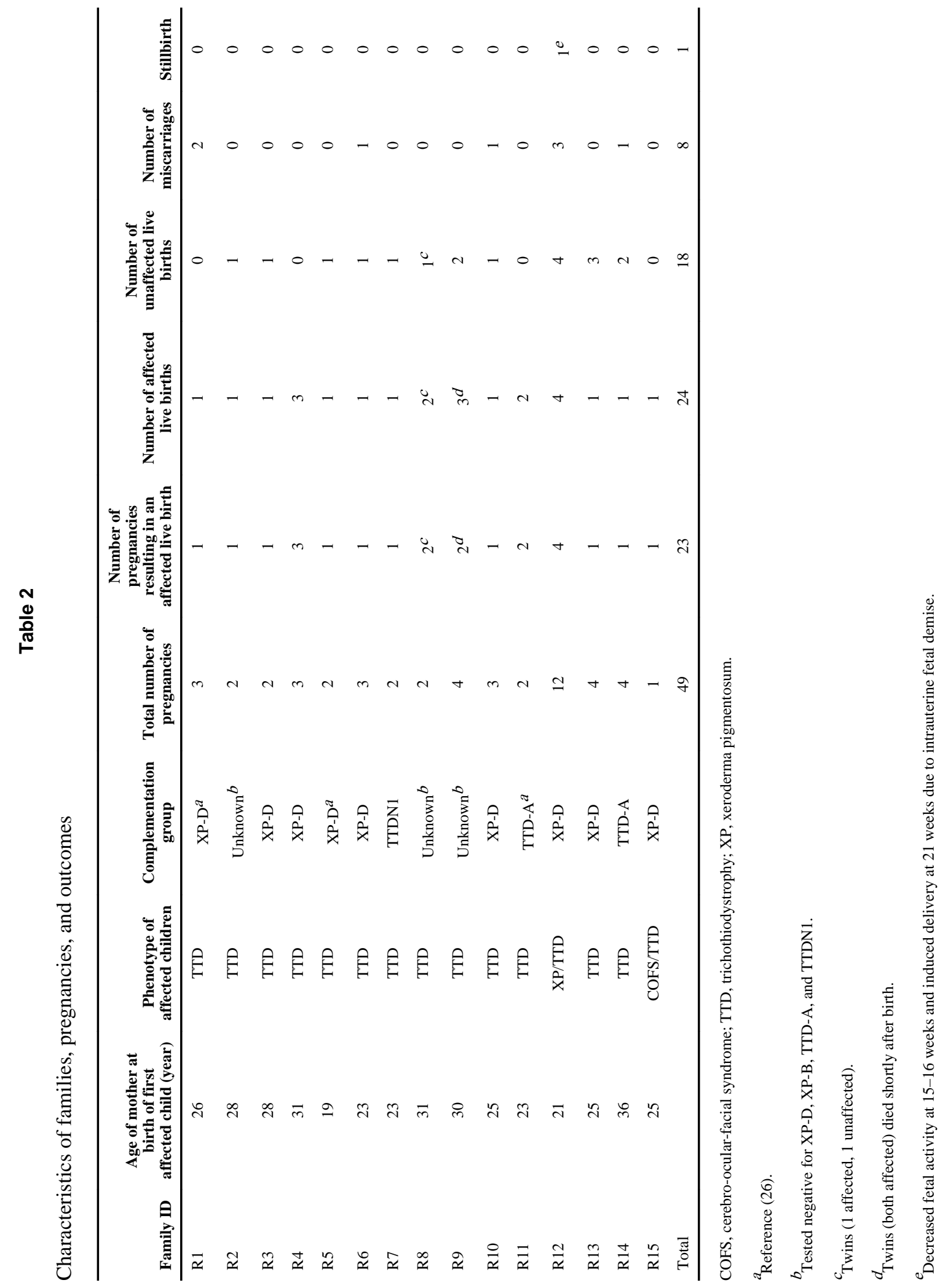


Table 3

Features of pregnancies resulting in live births $(n=42)$ of carrier mothers $(n=15)$

\begin{tabular}{|c|c|c|c|c|}
\hline & Affected $(n=24) \mathrm{N}(\%)$ & Unaffected $(n=18) \mathrm{N}(\%)$ & $\mathbf{R R}(\mathbf{9 5 \%} \mathbf{C I})$ & p-value \\
\hline \multicolumn{5}{|l|}{ Gender } \\
\hline Male & $13(54.2)$ & $10(55.6)$ & $1.0(0.6-1.7)$ & 1.00 \\
\hline Female & $11(45.8)$ & $8(44.4)$ & & \\
\hline \multicolumn{5}{|c|}{ Twin births } \\
\hline Yes & $3(12.5)$ & $1(5.6)$ & $2.0(0.2-20.7)$ & 0.57 \\
\hline No & $21(87.5)$ & $17(94.4)$ & & \\
\hline \multicolumn{5}{|c|}{ Pre-eclampsia } \\
\hline Yes & $7(25.0)$ & $1(5.6)$ & $5.2(0.4-61.3)$ & 0.19 \\
\hline No & $17(70.8)$ & $17(94.4)$ & & \\
\hline \multicolumn{5}{|c|}{ Hemolysis, elevated liver enzymes and low platelets (HELLP) syndrome } \\
\hline Yes & $3(12.5)$ & 0 & & \\
\hline No & $21(87.5)$ & $18(100.0)$ & & \\
\hline \multicolumn{5}{|c|}{ Decreased fetal movement reported by mother to physician } \\
\hline Yes & $9(37.5)$ & $1(5.6)$ & $6.3(0.9-45.0)$ & 0.07 \\
\hline No & $15(62.5)$ & $17(94.4)$ & & \\
\hline \multicolumn{5}{|c|}{ Abnormal levels of maternal serum screening markers $(n=11)$} \\
\hline Yes & $6(85.7)^{a}$ & 0 & & \\
\hline No & 1 & $4(100.0)$ & & \\
\hline \multicolumn{5}{|c|}{ Pre-term delivery (<37 weeks gestation) } \\
\hline Yes & $11(45.8)$ & $2(11.1)$ & $2.9(1.0-8.8)$ & 0.06 \\
\hline No & $13(54.2)$ & $16(88.9)$ & & \\
\hline \multicolumn{5}{|c|}{ Low birth weight $(<2500 \mathrm{~g})$} \\
\hline Yes & $15(62.5)$ & $2(11.1)$ & $3.5(1.1-11.0)$ & 0.03 \\
\hline No & $9(37.5)$ & $16(88.9)$ & & \\
\hline \multicolumn{5}{|c|}{ Small for gestational age (SGA) ( $<10$ th percentile) } \\
\hline Yes & $13(54.2)$ & $1(5.6)$ & $9.3(1.4-60.5)$ & 0.02 \\
\hline No & $11(45.8)$ & $17(94.4)$ & & \\
\hline \multicolumn{5}{|c|}{ SGA (<3rd percentile) } \\
\hline Yes & $10(41.7)$ & $1(5.6)$ & $7.2(1.1-48.1)$ & 0.04 \\
\hline No & $14(58.3)$ & $17(94.4)$ & & \\
\hline \multicolumn{5}{|c|}{ Neonatal intensive care unit (NICU) hospitalization } \\
\hline Yes & $15(62.5)$ & $1(5.6)$ & $6.4(1.4-29.5)$ & 0.02 \\
\hline No & $9(37.5)$ & 17 (94.4) & & \\
\hline
\end{tabular}

${ }^{a}$ Human chorionic gonadotropin (hCG) levels were elevated in all six. Alpha-fetoprotein levels were elevated in one and reduced in three of the affected pregnancies 
Table 4

Comparison of TTD-affected pregnancy characteristics to reference values

\begin{tabular}{|c|c|c|c|c|}
\hline & Affected $(n=24) \mathrm{N}(\%)$ & Reference Values ${ }^{a}(\%)$ & RR $(95 \%$ CI $)$ & p-value \\
\hline \multicolumn{5}{|l|}{ Gender } \\
\hline Male & $13(54.2)$ & $(51.1)$ & $1.1(0.7-1.4)$ & 0.84 \\
\hline Female & $11(45.8)$ & $(48.9)$ & & \\
\hline \multicolumn{5}{|l|}{ Twin gestation } \\
\hline & $3(12.5)$ & (2.6) & $5.5(1.7-12.0)$ & 0.023 \\
\hline \multicolumn{5}{|l|}{ Delivery } \\
\hline Vaginal & $15(62.5)$ & $(78.7)$ & & \\
\hline Cesarean & $9(37.5)$ & $(20.5)$ & $1.9(1.0-2.8)$ & 0.072 \\
\hline \multicolumn{5}{|c|}{ Hemolysis, elevated liver enzymes and low platelets (HELLP) syndrome } \\
\hline & $3(12.5)$ & $(0.35)$ & $35.7(7.6-92.5)$ & 0.0002 \\
\hline \multicolumn{5}{|c|}{ Elevated human chorionic gonadotropin (hCG) on maternal serum screening $(n=7)$} \\
\hline & $6(85.7)$ & (6) & $14.3(7.0-16.6)$ & $<0.0001$ \\
\hline \multicolumn{5}{|l|}{ Birth weight $b$} \\
\hline & $2215 \pm 990.1 \mathrm{~g}$ & $3353 \pm 581 \mathrm{~g}$ & & $<0.0001$ \\
\hline \multicolumn{5}{|c|}{ Low birth weight $(<2500 \mathrm{~g})$} \\
\hline & $15(62.5)$ & $(6.9)$ & $9.2(6.2-11.5)$ & $<0.0001$ \\
\hline \multicolumn{5}{|c|}{ Very low birth weight $(<1500 \mathrm{~g})$} \\
\hline & $5(20.8)$ & $(1.4)$ & $16.3(6.7-29.5)$ & $<0.0001$ \\
\hline \multicolumn{5}{|c|}{ Small for gestational age (SGA) } \\
\hline$<10$ th percentile & $13(54.2)$ & (10) & $5.4(3.3-7.4)$ & $<0.0001$ \\
\hline$<3$ rd percentile & $10(41.7)$ & (3) & $13.9(7.4-21.1)$ & $<0.0001$ \\
\hline \multicolumn{5}{|l|}{ Pre-term delivery } \\
\hline$<37$ weeks & $11(45.8)$ & $(10.9)$ & $4.3(2.6-6.0)$ & $<0.0001$ \\
\hline$<32$ weeks & $5(20.8)$ & (1.9) & $12.0(4.9-21.6)$ & $<0.0001$ \\
\hline \multicolumn{5}{|c|}{ Pre-eclampsia $(n=23)$} \\
\hline & $6(26.1)$ & $(6.5)$ & $4.0(1.6-7.4)$ & 0.006 \\
\hline \multicolumn{5}{|c|}{ Decreased fetal movement } \\
\hline & $9(37.5)$ & (11.5) & $3.3(1.6-5.2)$ & 0.0018 \\
\hline
\end{tabular}

a Elevated human chorionic gonadotropin (hCG) (20); pre-eclampsia (22); HELLP (23); decreased fetal movement (24); all others based on 1996 US population rates (19).

$b_{\text {Values for birth weight are mean } \pm \mathrm{SD}}$ 